\title{
Potroclival Meningioma Presenting as Foster Kennedy Syndrome: A Rare Manifestation
}

\section{Sulena, A.K.Sharma, R.K.Sureka}

From the Department of Neurology, Sawai Man Singh Medical College, Jaipur, Rajasthan-302004, India.

\section{Abstract:}

Foster Kennedy syndrome is combination of optic atrophy of one eye and papilloedema of the other eye. It is seen in 1-2.5\% of intracranial masses mainly meningiomas but association with petroclival meningioma has not been reported. Petroclival meningioma is a relatively rare tumor constituting about $1 \%$ of all meningiomas. We report a case of petroclival meningioma presenting as Foster Kennedy syndrome.

Key words: Eye, Meningeal Neoplasms, Optic Atrophy, Papilledema, Optic Nerve Diseases, Meningioma, Humans.

\section{Introduction}

Foster Kennedy syndrome is a rare constellation of clinical symptoms and signs presenting with a combination of optic atrophy of one eye and papilloedema of the other eye. The etiology varies from neoplasm to vascular lesions, meningitis, internal carotid artery stenosis and Paget's disease of the skull, tumors being the most common. Various tumors associated are sphenoid wing meningioma, frontal lobe glioma, optic neuroglioma, olfactory and chiasmal glioma, and craniopharyngioma $[1,2]$. To our knowledge, petroclival meningioma has not been described as cause of Foster Kennedy syndrome. We report this rare case of Foster Kennedy syndrome caused by a petroclival meningioma.

\section{Case Report}

A 45 year old female presented with complaints of bilateral progressive loss of vision in both eyes for last one month. This was accompanied with dull continuous type of right sided headache. On examination, visual acuity was no perception of light in the right eye and hand movements close to face in the left eye. There was relative afferent pupillary defect on the right side. Anterior segment and extraocular movements were within normal limits. Fundus showed optic atrophy on the right side and papilloedema on the left side [Fig. 1a,b]. Clinical diagnosis of Foster Kennedy syndrome was made. Neurological examination revealed no localising or lateralising signs. CT head showed hypodensity along right lateral aspect of clivus and adjacent petrous bone [Fig. 2a]

MRI brain [Fig.2b,c] revealed large intracranial enhancing mass lesion along right lateral aspect of clivus and adjacent petrous bone with extension into upper cervical region along pictorial

\section{Corresponding Author: Dr. Anjani K Sharma}

Email: anjanijpr@gmail.com

Received: October 28, 2014 | Accepted: January 29, 2015 | Published Online: March 5, 2015

This is an Open Access article distributed under the terms of the Creative Commons Attribution License (creativecommons.org/licenses/by/3.0)

Conflict of interest: None declared | Source of funding: Nil | DOl: http://dx.doi.org/10.17659/01.2015.0026 

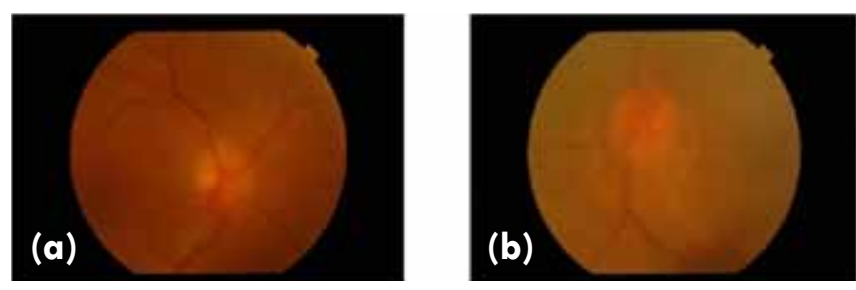

Fig.1a: Right eye optic disc shows pale optic disc. (1b) Left eye optic disc shows disc edema.

membrane which was iso-intense to grey matter on T1 and T2 causing mass effect with changes in brainstem, dilatation of bilateral lateral and third ventricles, all suggestive of petroclival meningioma. MRI orbit showed bilateral distension of optic sheath with CSF. Other investigations including hematological, biochemical, metabolic profile and ECG, CRP were unremarkable.

In view of presentation with ipsilateral optic atrophy and contralateral disc oedema along with features of raised ICP confirmed the diagnosis of Foster-Kennedy syndrome, an unusual presentation of petroclival meningioma.

\section{Discussion}

Foster Kennedy syndrome is seen secondary to intracranial mass, in which one optic disc is atrophic because of chronic compression by the mass, whereas the other disc is edematous because of raised intracranial pressure. Unilateral optic atrophy with contralateral papilledema and anosmia was first fully described by Kennedy in 1911, also known as Gower-Paton-Kennedy syndrome [3]. Anosmia is often included in the syndrome but its presence has not been universally reported as in our patient.

Foster Kennedy syndrome is known to be caused by multiple intracranial pathologies, commonest being meningiomas which includes sphenoid wing meningioma, frontal lobe glioma,
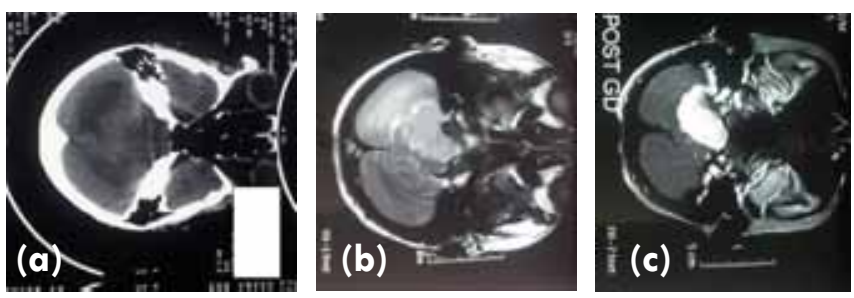

Fig.2a: CT scan at presentation. (2b) MRI post contrast images showing extent of tumor. (2c) MRI T2 weighed showing extent of tumor.

optic neuroglioma, olfactory glioma, chiasmal glioma, craniopharyngioma and even vascular lesions, meningitis, internal carotid artery sclerosis, and Paget's disease of the skull but association with petroclival meningioma has not been reported [4].

Petroclival meningiomas follow the pattern of other meningiomas in their 2:1 female-tomale ratio [5]. The average age of presentation is the mid-forties as in our case. The neurologic presentation of patients with petroclival meningioma varies and are due to increased intracranial pressure (ICP), involvement of the cranial nerves, cerebellar compression, or compression of the brain stem. Hakuba et al. reported 44 cases of petroclival meningiomas where presentation was due to increased ICP $(70 \%)$, cerebellar involvement $(70 \%)$, involvement of the trigeminal nerve $(68 \%)$, eighth nerve $(64 \%)$, facial nerve palsy $(57 \%)$, and corticospinal tract dysfunction (57\%) [6].

This patient's presentation differed from the usual clinical presentation in that she did not have any other symptoms of increased intracranial pressure such as nausea or vomiting except for mild headache of one month. Her main reason for presentation was progressive bilateral visual disturbance. She did not have any other neurological deficits. To best of our knowledge, the reported presentation of Foster Kennedy syndrome due to petroclival meningioma is quite rare. 


\section{Conclusion}

The fact that petroclival meningioma presenting as Foster Kennedy syndrome is rare, awareness is important to provide a better outcome for patients. Since multiple intracranial pathologies have been described for Foster Kennedy syndrome, unusual causes of the syndrome should be entertained while investigating for the cause of same for early diagnosis and treatment.

\section{References}

1. Von Wowern F. The Foster Kennedy syndrome: an evaluation of its diagnostic value. Acta Neurol Scand. 1967;43:205-214.

2. Castellano F, Ruggiero G. Meningiomas of the posterior fossa. Acta Radiol. 1953;104:1-117.
3. Kennedy F. Retrobulbar neuritis as an exact diagnostic sign of certain tumours and abscesses in the frontal lobe. American J Medical Sciences. $1911 ; 142: 355-368$.

4. Bhura P, Mishra RK. Foster Kennedy syndrome. Indian Journal of Ophthalmology. 1973;21:3233.

5. Cushing $\mathrm{H}$, Eisenhardt L. Meningiomas of the cerebellar chamber. In: Cushing $\mathrm{H}$, Eisenhardt L: Meningiomas: their classification, regional behaviour, life history, and surgical end results. Springfield, Illinois: Charles C. Thomas, 1938:169.

6. Hakuba A, Nishimura S, Tanaka K, Kishi H, Nakamura 1'. Clivus meningioma: Six cases of total removal. Neurol Med Chil' (Tokyo). 1977;17:63. 